\title{
Prostaglandins and mucosal defensive mechanisms
}

\author{
Gerald P Morris, PhD, Todd E Williamson, MSc, Taimi T Hynna, MSc
}

\begin{abstract}
The first line of mucosal defence includes the juxtamucosal unstirred layer/pH gradient and the apical surfaces of the luminal epithelial cells. Many damaging agents, including nonsteroidal anti-inflammatory drugs (NSAIDs), can overwhelm these defences and destroy extensive regions of the luminal epithelium. This damage is readily tolerated in the normal mucosa. Furthermore, a combination of increased mucosal bloodflow, epithelial migration, mucus release, and efflux of bicarbonate-rich fluid usually allows rapid recovery of mucosal integrity. In the presence of vascular damage and congestion, however, luminal acid can kill mucosal cells and destroy the substrate necessary for repair (by epithelial migration). Damage of this type results in the production of hemorrhagic erosions, which may then develop into chronic ulceroinflammatory disease if healing is prevented by excess luminal acid or by impaired mucosal immune response. Endogenous and exogenous prostaglandins could affect all aspects of the mucosal defensive responses, from the juxtamucosal unstirred layer/pH gradient (via effects on secretion of bicarbonate, acid and mucus, as well as stimulation of fluid efflux) to the function of the mucosal immune system. Protection against the acute damage produced by topically administered NSAIDs or concentrated ethanol can result from either administration of prostaglandins or topical application of 'mild irritants'. This is referred to as 'adaptive cytoprotection'. Parenterally administered NSAIDs can also produce mucosal erosions. Protection against this type of damage may depend on the effects of prostaglandins on neural and contractile elements in the mucosa. Studies on animal models also suggest that by preventing acute hemorrhagic erosions, prostaglandins may prevent the development of chronic ulcer in susceptible individuals. Can J Gastroenterol 1990;4(3):95-107
\end{abstract}

Key Words: Adaptive cytoprotection, Cytoprotection, Gastric ulcer, Microvasculature, Mucus-bicarbonate barrier, Prostaglandin, Unstirred water layer

\section{Les prostaglandines et les mécanismes de défense de la muqueuse}

RESUME: La première ligne de défense de l'estomac est le gradient de $\mathrm{pH}$ de la couche juxtamuqueuse non perturbée et la surface externe des cellules épithéliales. De nombreux agents nocifs, parmi lesquels les anti-inflammatoires non stéroïdiens (AINS), peuvent anéantir ces facteurs de protection et détruire

Gastrointestinal Disease Research Unit and Department of Biology, Queen's University, Kingston, Ontario

Correspondence and reprints: Dr GP Morris, Department of Biology, Queen's University, Kingston, Ontario K7L 3N6. Telephone (613) 545-6130. Fax (613) 545-6617
S UPPRESSION OF ACID SECRETION BY $\mathrm{H}_{2}$ receptor antagonists remains the basis for current therapy of peptic ulcer. The most obvious and well defined therapeutic value of prostaglandins in the treatment of peptic ulcer results from their antisecretory properties (1). By decreasing the quantity and concentration of secreted acid, prostaglandins can promote healing of peptic ulcer and minimize the production of acute damage produced by agents such as aspirin. When viewed solely in terms of ability to suppress acid secretion, prostaglandins do not offer significant therapeutic advantages over the $\mathrm{H}_{2}$ receptor antagonists. It is becoming apparent, however, that prostaglandins have other potentially beneficial effects on the mucosa, independent of their effects on acid secretion, which may justify their use in certain clinical settings as alternatives to other therapies. In particular, prostaglandins have been shown to affect the function of several aspects of mucosal defence.

Gastrointestinal mucosal defences are dynamic rather than static barriers. Successive levels of defences must be overcome during the transition from a broken mucosal barrier to acute erosion and finally chronic ulceroinflammatory disease (Figure 1). By defining these defences and identifying the agents and mediators which overcome or impair them, it is possible to identify sites and stages at which the mucosa is vulnerable and at which therapeutic inter- 
des régions importantes du revêtement épithélial. Ce dommage est facilement toléré dans des conditions normales. De plus, l'augmentation de l'apport sanguin au niveau des muqueuses, la migration épithéliale, la production de mucus et l'afflux d'un liquide riche en bicarbonates conjuguent leur action pour permettre habituellement à la muqueuse de retrouver rapidement son intégrité. En présence de lésion vasculaire et de congestion, néanmoins, l'acide gastrique peut détruire les cellules de la muqueuse et le substrat nécessaire à la régénération épithéliale. Si l'excès d'acide gastrique ou une défaillance de la réponse immunitaire de la muqueuse empêche la cicatrisation, il se produit des érosions hémorragiques qui peuvent ensuite résulter en une affection ulcéro-inflammatoire. Les prostaglandines endogènes et exogènes pourraient bien affecter tous les aspects des réponses défensives de la muqueuse, à commencer par le gradient de $\mathrm{pH}$ de la couche juxtamuqueuse non perturbée (par leurs activités sur la sécrétion de bicarbonates, d'acide et de mucus, ainsi que la stimulation de l'afflux liquide) et jusqu'à la fonction du système immunitaire de la muqueuse. La prévention de tout dommage grave provoqué par les AINS ou l'alcool concentré peut s'obtenir en administrant soit des prostaglandines soit des 'irritants doux' - c'est à dire par 'cytoprotection adaptative.' Les AINS pris par voie parentérale peuvent aussi entraîner l'érosion de la muqueuse. La protection peut dans ce cas dépendre des effets des prostaglandines sur les éléments nerveux et contractiles de la muqueuse. Certaines études chez l'animal suggèrent également qu'en prévenant les érosions hémorragiques aiguës, les prostaglandines empêchent peut-être le développement de l'ulcère chronique chez les sujets sensibles.

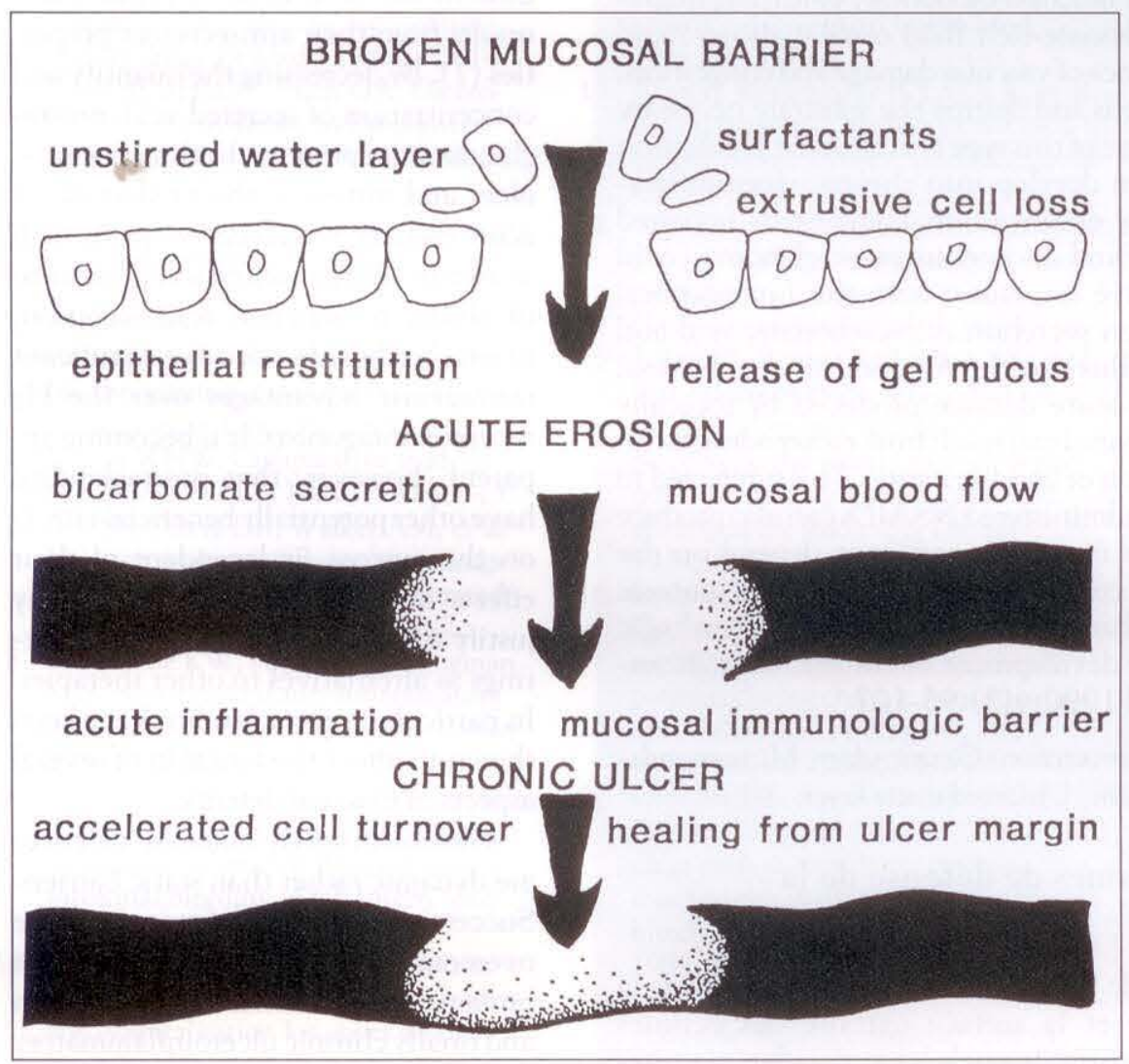

Figure 1) Diagrammatic representation of gastric mucosal defences and the types of damage which may result when successive layers of defences are overcome. The locations of various defences on the diagram (corresponding to sites in or external to the surface epithelium and within the mucosa, submucosa and muscularis) indicate the approximate depth of damage as each successive set of defences is overcome. The components of each defensive response (such as the immunologic barrier or accelerated cell turnover) can occur throughout the depth of the gastric wall vention could prevent progression from readily repaired superficial damage to chronic ulcer.

Prostaglandins have trophic and immunomodulatory effects. They can: stimulate secretion of mucus and bicarbonate; increase mucosal bloodflow; af fect electrogenic ion transport; and both stimulate and inhibit gastrointestinal motility (2). Prostaglandins are also produced in concert with many other mediators of inflammation such as leukotrienes and platelet activating factor, and may affect their production or actions.

Thus, prostaglandins can affect all stages in the progression of injury and may not only prevent the initial development of acute injury, but also aid in healing and preventing relapse.

\section{PROSTAGLANDINS AND CYTOPROTECTION}

The demonstration that prostaglandins have both antisecretory and antiulcer activities in animal models $(1,3)$, and that certain synthetic prostaglandins are much more potent antisecretory agents than natural prostaglandins (4), suggested that these agents may be of therapeutic value in the reduction of gastric acid secretion. A subsequent study demonstrated that 'cytoprotective' prostaglandins could also prevent the development of acute hemorrhagic erosions produced in the gastric mucosa by necrotizing agents such as concentrated ethanol and strong acids (5). This study provided further support for a potential therapeutic role of these compounds in the treatment of ulceroinflammatory diseases of the upper gastrointestinal tract. Since the cytoprotective properties of prostaglandins were manifested at doses below those which were antisecretory, it seemed that a new therapeutic approach was feasible.

It was also apparent that many agents other than prostaglandins were cytoprotective. When applied to the gastric mucosa prior to necrotizing agents, so-called 'mild irritants' were shown to produce 'cytoprotection' equivalent to that provided by exogenous prostaglandins (6). This gave rise to the concept of 'adaptive cyto- 


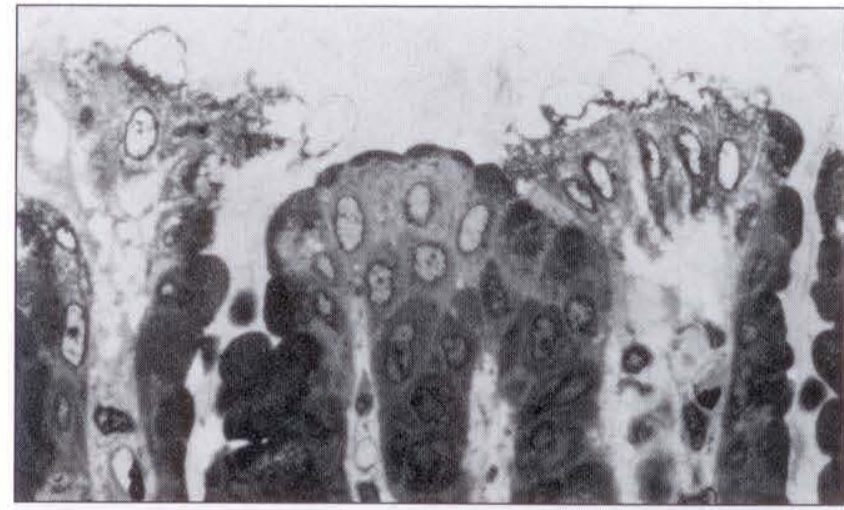

Figure 2) Light micrograph of rat fundic mucosa, 5 mins after exposure to $9 \%$ ethanol containing $16 \mathrm{mM}$ acetylsalicylic acid. Interfoveolar epithelial cells are irreversibly damaged and are being shed from the mucosa. (Plastic section stained with toluidine blue $\times 540$ )

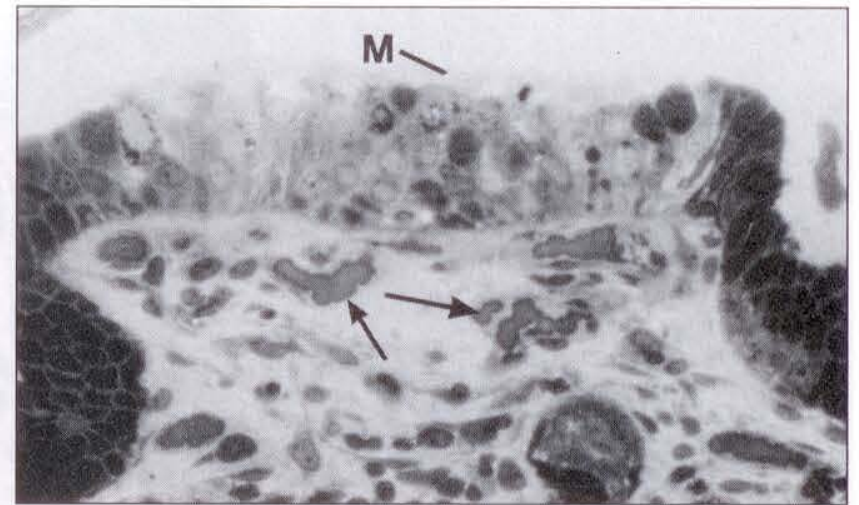

Figure 3) Light micrograph of a biopsy of human antral mucosa 10 mins after exposure to $40 \%$ ethanol. Arrows indicate congested subepithelial collecting venules. Ultrastructural study indicated that most of the interfoveolar cells were irreversibly damaged. A local, adherent mucus coat (M) has been released from the damaged epithelial cells. (Plastic section stained with toluidine blue $\times 350$ ) protection'. Adaptive cytoprotection was initially found to be abolished by the pretreatment of animals with inhibitors of cyclo-oxygenase activity. This was interpreted as evidence that protection depended on irritantinduced stimulation of prostaglandin synthesis. Elevated prostaglandin synthesis has also been invoked as an explanation for the cytoprotective actions of agents such as sucralfate and the aluminum-containing antacids $(7,8)$.

It has proven difficult, however, to provide convincing explanations for the mechanisms which underlie the phenomenon of cytoprotection. Cytoprotection by prostaglandins in the gastric mucosa is clearly not dependent on the preservation of the integrity of the surface epithelium in the face of assault by barrier breakers, but rather results from the prevention of microvascular disruption and the maintenance of gastric mucosal bloodflow (9). In this sense, most experiments have demonstrated indirect cytoprotection where preservation of mucosal integrity is a consequence of effects on the mucosal microvasculature. Furthermore, adaptive cytoprotection can occur even when prostaglandin synthesis is significantly inhibited by prior administration of indomethacin (1012). It is also necessary to consider the means by which agents other than prostaglandins can prevent microvascular disruption.
There is evidence that prostaglandins exert limited direct cytoprotection on in vivo gastric mucosal preparations and gastric cells which are isolated or maintained in cell culture $(13,14)$. Such protection has been demonstrated against nonsteroidal anti-inflammatory drugs (NSAIDs), ethanol and taurocholate, and could play a role in the survival of certain populations of mucosal cells following exposure to damaging concentrations of these necrotizing agents (13-15). Studies on in vivo systems have demonstrated that direct cytoprotection of the luminal epithelium of the stomach against concentrated ethanol can be achieved by prior exposure to a mild irritant (11) or to sucralfate (12). This may be due to a 'histodilutional' effect (16), whereby the presence of an irritant-induced fluid efflux and edema, or a protective covering of sucralfate and mucus, attenuates the concentration of ethanol which comes into contact initially with the mucosa. There is no reason to believe that the luminal epithelium is rendered resistant to concentrated ethanol.

\section{PROSTAGLANDINS AND REPAIR OF SUPERFICIAL DAMAGE BY RESTITUTION}

Superficial damage to the stomach, of the type readily produced by barrier breakers such as acidified aspirin, sodium taurocholate, and concentrated ethanol may result in destruction of most of the luminal epithelium (Figures $2,3)$. Although this damage is irreversible at the cellular level, it is often restricted to luminal epithelial cells. If gastric mucosal microcirculation is not impaired, this type of damage is readily repaired or restored by cell migration from gastric glands (17). The restitution process is rapid and typically complete in about $1 \mathrm{~h}$ in both the stomach and small intestine.

Superficial injury is usually followed by increased gastric mucosal bloodflow which, in combination with a cap of exfoliated cells and mucus, provides a localized alkaline microenvironment within which the influxing acid can be neutralized (17). Although it may be widespread, superficial damage to the epithelium must be considered a normal event and does not usually produce ulceration. Such injury is a result of the ready entry into cells of the undissociated lipophilic salicylate molecule, the detergent effects of bile salts, or osmotic damage in the case of hypertonic solutions. In the case of acetylsalicylic acid (ASA), once absorbed into the cells of the gastric epithelium, the molecule encounters a near neutral $\mathrm{pH}$ and reverts to the ionized form, resulting in disruption of the intracellular ionic balance and localized accumulation of acid.

ASA also produces extensive and rapid damage to the intestine within minutes. In one study on humans, a 


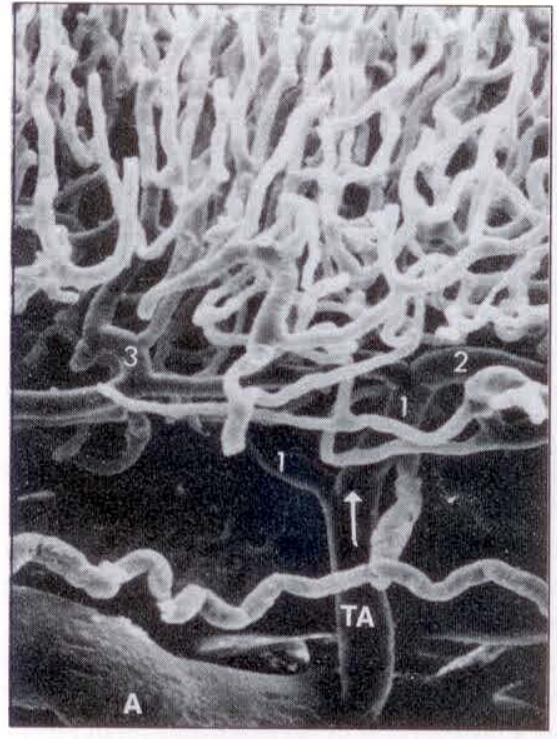

Figure 4) Scanning electron micrograph of corrosion cast of rat gastric mucosa showing submucosal artery (A) and terminal arteriole (TA) at the base of the mucosa. The terminal arteriole forms primary (1), secondary (2) and tertiary (3) branches which give rise to the mucosal capillaries (X245)

dose of ASA equivalent to two tablets in a glass of water damaged 25 to $30 \%$ of jejunal villi within 5 mins (18). Similar levels of damage have been produced in the proximal jejunum following exposure to intraluminal ethanol at peak concentrations of about $6 \%$ (19). As in the stomach, this type of damage was most frequent in the oldest cells (at the villus tips) and accompanied by blistering and rupture. Ivey et al (18) also found a $20 \%$ incidence of duodenal lesions by endoscopy in rheumatic disease patients receiving chronic ASA therapy. They noted that although enteric-coated ASA significantly reduced gastric mucosal damage, the incidence of duodenal erosions remained at about $20 \%$.

Successful repair by restitution depends on either an absence of luminal acid or an intact mucosal microvascular supply which maintains a supply of bicarbonate-rich fluid to the overlying layer of damaged cells and released mucus. In the presence of vascular congestion, acid not only kills cells but also destroys the basal lamina (basement membrane), which is a substrate necessary for cell migration (17). Following



Figure 5) Scanning electron micrograph of corrosion cast of rat fundic mucosa. A submucosal artery (A) gives rise to arterioles (one of which is indicated by an arrow), which produce capillaries (CAP) The capillaries connect with the collecting venules (CV) near the mucosal surface. Collecting venules drain into a venous plexus (vp) which lies at the base of the mucosa. The vein (v) penetrates the muscularis mucosa and drains the venous plexus (x106)

exposure to prostaglandins, however, the mucosa is typically resistant to vascular damage and rapid repair can proceed. It is still not clear precisely how the administration of prostaglandins or mild irritants prevents necrotizing agents from causing vascular damage. It is clear, however, that the end result is the preservation of microvascular integrity.

\section{ULTRASTRUCTURE OF GASTRIC MUCOSAL MICROCIRCULATION}

The most revealing method for visualizing the architecture of the gastrointestinal microcirculation is that of scanning electron microscopy (SEM) of corrosion casts. With this technique, the microvasculature is perfused with saline followed by low viscosity plastic. The plastic is allowed to polymerize, the tissue digested, and the resulting casts viewed by SEM. The microvascular architecture of human and rat stomachs is basically the same $(20,21)$. At the mucosal base, primary, secondary, and tertiary branches of mucosal arterioles give rise to an ascending capillary arcade (Figures 4, 5). The capillary arcade connects with the collecting venules in the upper regions of the mucosa (Figure 5). There are no lateral interconnections between the ascending capillaries and the collecting venules. However, the interconnections between the capillaries and the multiple connections of the capillaries with the collecting venules result in considerable redundancy (Figure 6).

An additional level of redundancy is introduced by the formation of large branches by many of the collecting venules. In the rat fundus, the authors found that almost half $(44.8 \pm 3.4 \%)$ of the collecting venules were formed by fusion of major branches (Figure 7). More than $95 \%$ of these major branches 


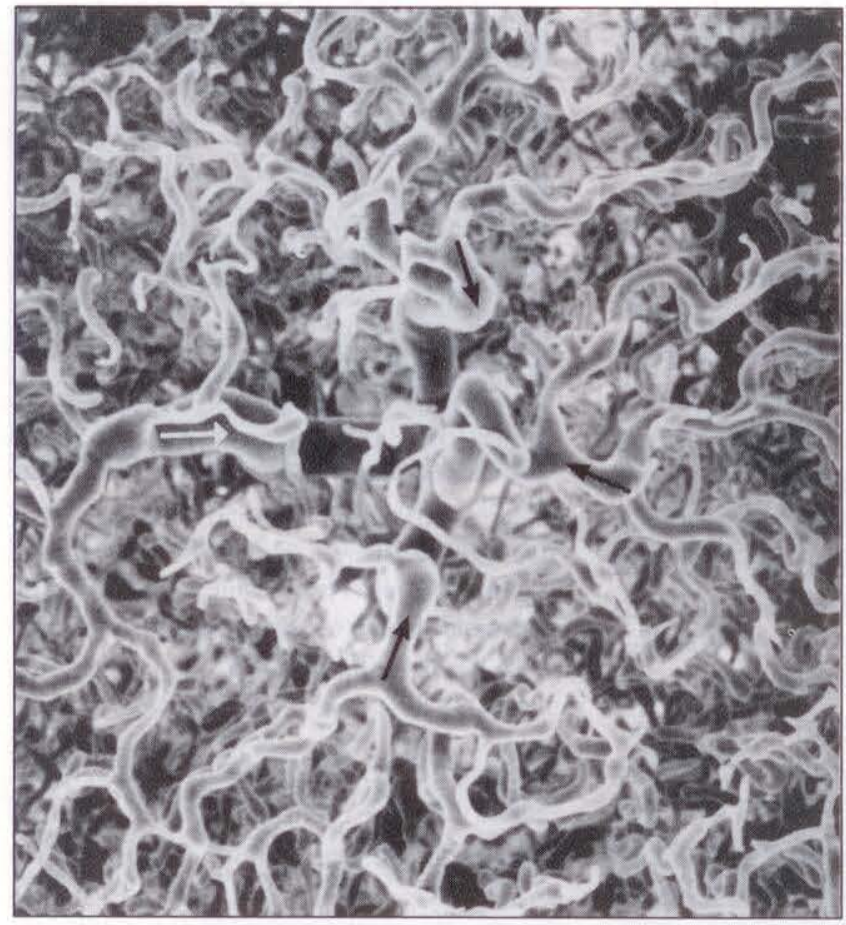

Figure 6) Scanning electron micrograph of luminal surface of corrosion cast of rat fundic mucosa. This view of the mucosal surface shows the honeycomb arrangement of the subepithelial capillaries and the interconnections between capillaries and a branched collecting venule. The four arrows indicate the major branches of the collecting venule and the direction of bloodflow (x170)

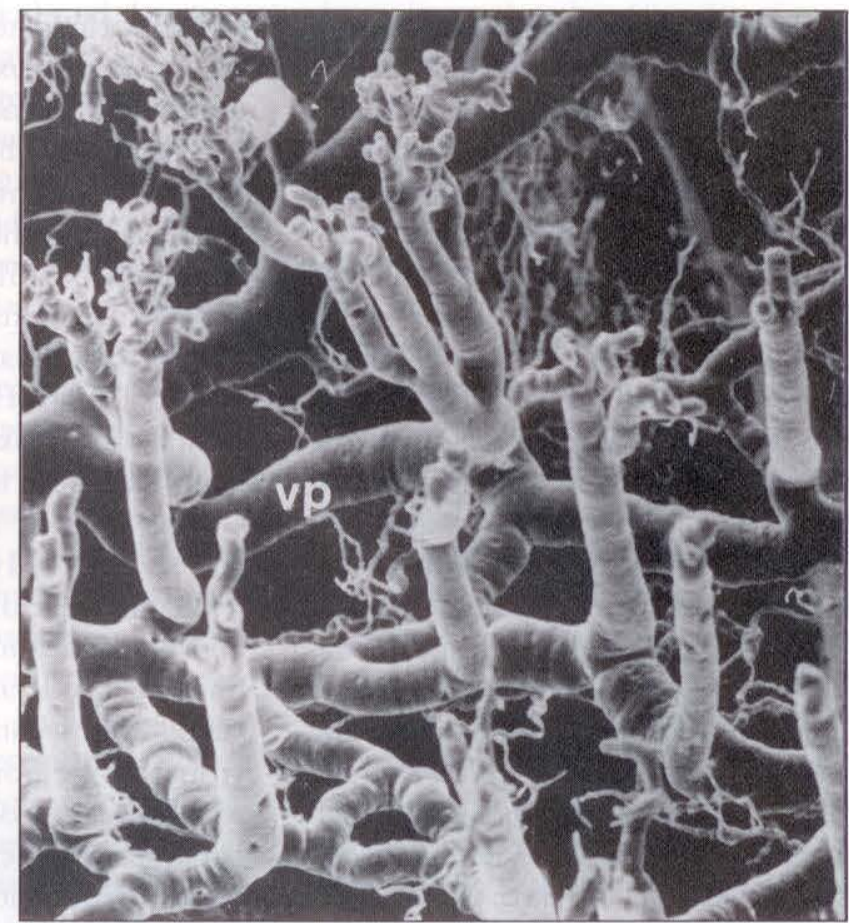

Figure 7) Scanning electron micrograph showing branching of collecting venules and venous plexus (vp) from rat fundic mucosa. This is a partial retrograde cast which was produced by infusion of plastic through the superior mesenteric vein. Perfusion was stopped before the capillary bed was filled (x100) converged in the upper two-thirds of the mucosa. The collecting venules drain into an anastomosing collecting venule plexus which lies at the base of the mucosa, adjacent to the muscularis mucosa (Figures 7,8). The mucosal microcirculation can thus tolerate numerous localized sites of congestion or damage to capillaries or collecting venules. Cessation of bloodflow and local ischemia in the vulnerable, subepithelial region will only occur when all of the branches feeding a collecting venule have been damaged or congested. Similarly, the redundancy in the

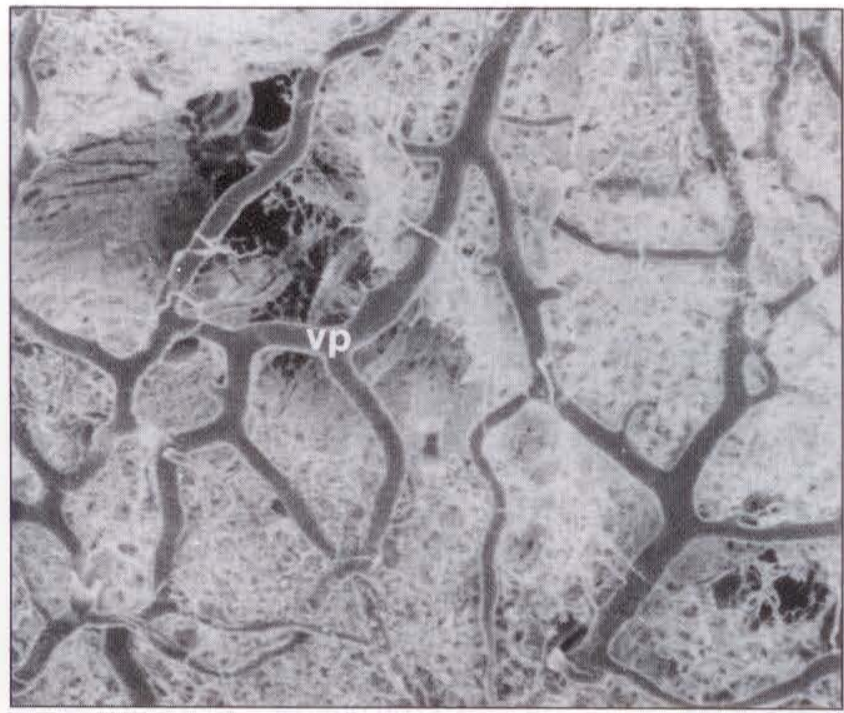

Figure 8) Scanning electron micrograph of venous plexus (vp). This is a view of the undersurface or serosal aspect of the mucosa. The vessels of the submucosa, muscularis and serosa were removed during preparation, and the image shows the interconnected nature of the venous plexus and the overlying capillary bed (x50)

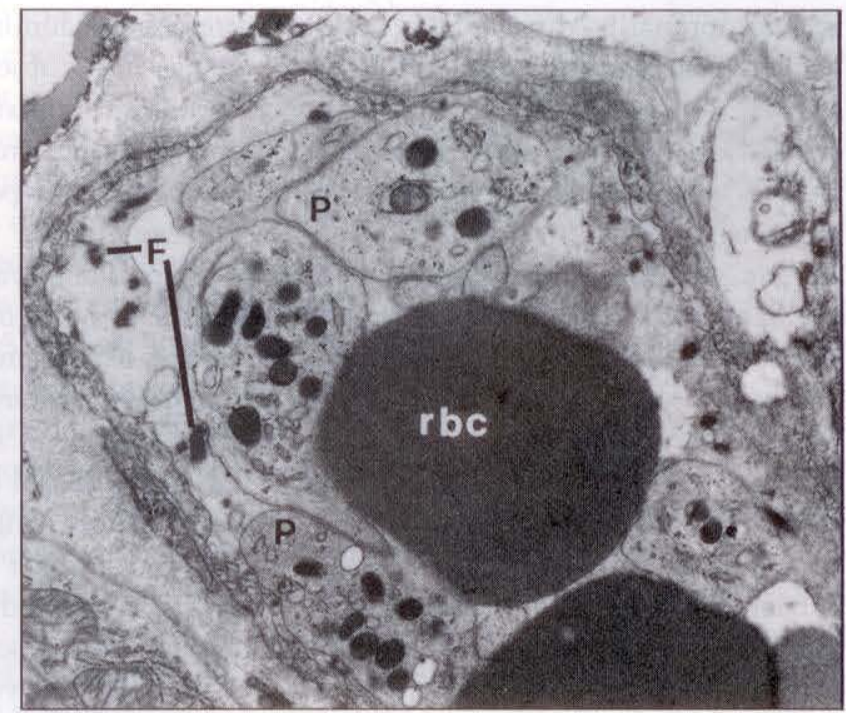

Figure 9) Transmission electron micrograph of a subepithelial collecting venule after exposure of the mucosa for 10 mins to $16 \mathrm{mM}$ ASA in 50 $\mathrm{mM}$ hydrochloric acid, and for a subsequent 5 mins to $50 \mathrm{mM}$ hydrochloric acid. Note red blood cells $(r b c)$, partially degranulated platelets $(P)$, and fibrin (F) deposition (X8400) 
underlying venular plexus ensures that drainage and perfusion will continue even when numerous individual collecting venules have become occluded. Sites of microvascular damage by topically applied aspirin: When acidified aspirin is placed on the gastric mucosa it produces, within minutes, extensive subepithelial platelet thrombi in the collecting venules (Figure 9). Aggregated platelets actively synthesize thromboxane $\mathrm{A}_{2}$, which is a potent vasodilator and itself a promoter of further platelet aggregation. Whittle et al (22) showed that when local intravascular synthesis of thromboxane $\mathrm{A}_{2}$ was stimulated, exposure of the canine stomach to concentrations of acid and bile salt ( $100 \mathrm{mM}$ hydrochloric acid and $5 \mathrm{mM}$ sodium taurocholate), which were normally tolerated, resulted in extensive mucosal bleeding.

The impairment of hemostatic mechanisms, which is usually associated with aspirin ingestion, results from a systemic effect, via O-acetylation of platelet cyclo-oxygenase activity. However, in the gastric and upper intestinal mucosae, the ASA molecule need only penetrate a single layer of epithelium and a few microns of extracellular matrix before coming into contact with the endothelial cells of the subepithelial capillaries and collecting venules. ASA can therefore rapidly damage primarily the vascular endothelial cell and inhibit prostacyclin synthesis. Thrombus formation, congestion and local tissue damage, in the form of petechiae or punctate erosions, result.

Effects of parenteral administration of NSAIDs and hypotension: Parenteral administration of aspirin and indomethacin caused antral ulcers in the stomachs of animals when doses were used that gave plasma levels considered therapeutic in humans. The ulcers appeared in advance of signs of a broken barrier and were not related to the presence of salicylates in the gastric lumen, although the presence of luminal acid was necessary for lesion formation (23). Furthermore, Whittle (24) demonstrated that while neither 2 $\mathrm{mM}$ sodium taurocholate, nor any one of four subcutaneously administered
NSAIDs (indomethacin, flurbiprofen, ASA, or naproxen), nor the vasoconstrictor noradrenaline, produced lesions, the combination of any of the NSAIDs or noradrenaline with acidified taurocholate was highly ulcerogenic. NSAIDs prevented the hyperemic response which normally follows topical damage. The result was the production of hemorrhagic erosions by a barrier breaker which would normally have been tolerated.

The present authors found that when ASA $(16 \mathrm{mM}$ in $50 \mathrm{mM}$ hydrochloric acid) was placed in the ex vivo gastric chamber for up to $30 \mathrm{mins}$, only small punctate erosions developed (unpublished data). Similarly, induction of hemorrhagic shock by withdrawal of blood to produce a rapid but transient decrease in mean blood pressure (to about $25 \mathrm{mmHg}$ ) produced few lesions and only temporary decrease in transmucosal potential difference. However, when ASA was placed in the chamber for 10 mins shortly after the induction of hemorrhagic shock, extensive ulcerations covering an average of $50 \%$ of the glandular mucosa resulted. These lesions first appeared as patches of intense focal pallor and were covered with a dense coagulum of extruded cells and mucus. This material covered regions of deep mucosal necrosis which ultimately became hemorrhagic in the presence of luminal acid. Such ulcers appear in the absence of diffuse damage and their genesis cannot readily be derived from consideration of the barrier-breaking hypothesis. They probably result from vascular blockade, perhaps due to vasoconstriction at the mucosal base or in the submucosa.

Effects of concentrated ethanol on the mucosal microcirculation: The present morphological studies suggest that ethanol-induced hemorrhagic erosions resulted from congestion or occlusion at the point where the mucosal venular plexus is drained by veins which pass through the muscularis mucosa (Figure 10). This is a vulnerable site in the mucosal circulation. Blockade by compression or congestion of these draining veins would affect relatively large areas of the mucosa. After exposure to concentrated ethanol, the sites which were

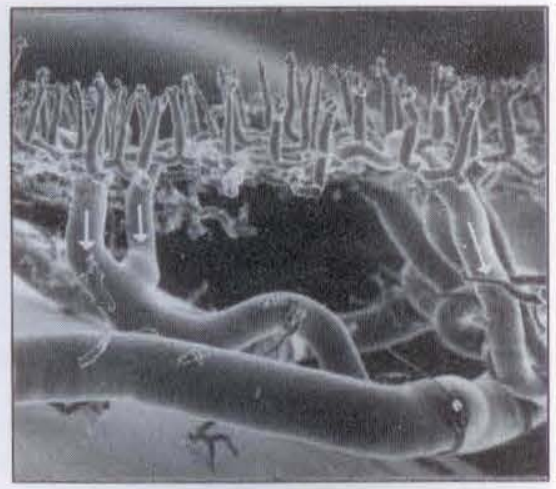

Figure 10) Scanning electron micrograph of lateral view of partial retrograde cast of mucosal venous system. Arrous indicate veins which drain blood from venous plexus into large submucosal veins ( $\times 25)$

destined to become hemorrhagic erosions were clearly visible because of their congested blood vessels. Submucosal arteries, mucosal capillaries and collecting veins were typically congested at these sites (9), but veins in the submucosa below the exit from the muscularis mucosa were empty of blood.

Oates and Hakkinen (25) have suggested a sequence of events which may lead to the production of ethanol-induced gastric lesions. They suggested that ethanol may act by causing mast cells to rapidly degranulate and release vasoactive mediators such as leukotriene (LT) $\mathrm{C}_{4}$ and histamine. These mediators could then induce venous constriction and gastric muscle contractions. They observed that arterial and arteriolar dilation occurred within 15 to $20 \mathrm{~s}$ of exposure of the stomach to ethanol, and that the combination of strong arterial/ arteriolar dilation and venous constriction produced vascular engorgement and visible hyperemia within $1 \mathrm{~min}$. Greatly elevated capillary pressure in the mucosa and enhanced permeability can produce mucosal edema with a resultant lifting and blistering of the epithelium. The authors' studies are in general agreement with these concepts $(26,27)$. The primary roles for mast cells and the production of $\mathrm{LTC}_{4}$, however, remain in doubt, since ethanol caused significant mast cell degranulation in cytoprotected mucosa (28) and there was no correlation between the ability of various cytoprotective agents to in- 
hibit LTC4 synthesis and their ability to protect the mucosa (29).

\section{LOCAL AND REFERRED CYTOPROTECTION: PROSTAGLANDIN-INDEPENDENT AND PROSTAGLANDIN. DEPENDENT}

A phenomenon which the authors have defined as 'referred cytoprotection' occurs at sites in the mucosa which are not in contact with the protective agent (30). In these studies, an ex vivo rat gastric chamber preparation was used (27). This preparation allows direct viewing of the mucosa and monitoring of physiological indicators of mucosal integrity during the periods in which protective agents are present and during the development of hemorrhagic erosions. By tilting the gastric chamber preparation at an angle of about $30^{\circ}$, it is possible to cover half of the mucosal surface with $1.0 \mathrm{~mL}$ of luminal solution. A 5 min exposure of half of the mucosa to the mild irritant $0.25 \mathrm{M}$ hydrochloric acid, for instance - produced referred cytoprotection against $40 \%$ ethanol. There was a highly signifificant reduction in the area of hemorrhagic erosions on both the side which was exposed to the irritant and the side which was not exposed. The authors have studied the effects of several cytoprotective agents, and some, such as $4 \%$ sodium chloride, produced only local protection against ethanol, while others produced referred protection (Williamson et al, manuscript submitted)

This model allowed the examination of changes which occurred in the half of the mucosa not exposed to irritant, and testing of the hypothesis that adaptive cytoprotection results from an increase in release of mucus or bicarbonate secretion. Consequently, neither of these changes occurred on the uncovered side which, although not directly exposed to the protective agents, was still protected against $40 \%$ ethanol. In addition, there was no increased mucus release and no change in the thickness of the juxtamucosal unstirred/alkaline layer.

Referred protection against ethanol was, however, blocked by parenteral in- domethacin $(5 \mathrm{mg} / \mathrm{kg})$ and dopamine $D_{1}$ and $D_{2}$ receptor antagonists. These studies suggest that referred protection is prostaglandin-dependent and that it involves dopaminergic neurons. Local protection on the side covered by the irritant or prostaglandins was not affected by indomethacin or dopamine receptor antagonists. The prostaglandindependence of referred protection and the ability of irritants to produce local protection in the presence of inhibition of cyclo-oxygenase may explain much of the controversy in the literature about the subject of whether adaptive cytoprotection against ethanol depends on prostaglandin synthesis. Referred protection depends on prostaglandin synthesis; local protection does not.

Referred protection was not, however, produced by either irritants or prostaglandins against acidified ASA or high concentration $(80 \mathrm{mM})$ sodium taurocholate, even though all of the mild irritants and prostaglandins which were studied provided local protection against these necrotizing agents. Furthermore, the irritants produced effective local protection even in animals pretreated with $5 \mathrm{mg} / \mathrm{kg}$ indomethacin. The failure to produce referred protection against $A S A$ and sodium taurocholate probably reflects the differing means by which these agents produce hemorrhagic lesions compared with concentrated ethanol. Ethanol produces vascular occlusion as a result of effects on vessels at the mucosal base or in the submucosa. The initiating event may be a constriction of draining venules or veins, as a result of either ethanol-induced mediator release or contraction of vessels of the muscularis mucosa. Acidified ASA and sodium taurocholate produce damage which is initially severe in the luminal epithelium, then progresses into the lamina propria, followed by an influx of luminal acid and damage to vascular elements such as the collecting venules.

\section{PROSTAGLANDINS AND THE MUCUS-BICARBONATE BARRIER}

It is widely believed that a protective $\mathrm{pH}$ gradient exists at the surface of the gastric mucosa. Turnberg and Ross (31) have shown that the $\mathrm{pH}$ at the mucosal surface can be as high as 6.7, even in the face of a luminal $\mathrm{pH}$ as low as $2.0(10$ $\mathrm{mM}$ hydrochloric acid). Once the luminal $\mathrm{pH}$ is decreased below $\mathrm{pH} 2.0$, however, the juxtamucosal $\mathrm{pH}$ gradient diminishes. At a luminal $\mathrm{pH}$ of 1.1 (80 $\mathrm{mM}$ hydrochloric acid) the gradient is completely abolished. These findings are of considerable interest and have done much to support the idea that the $\mathrm{pH}$ gradient is essential for mucosal defence and that the ability of prostaglandins to stimulate bicarbonate secretion is a major factor in explaining their cytoprotective abilities. However, it is difficult to understand how a $\mathrm{pH}$ gradient could affect entry of ethanol into the mucosa, and the authors have consistently obtained prostaglandin-induced protection against luminal necrotizing agents when the chambered gastric mucosa is bathed in $50 \mathrm{mM}$ hydrochloric acid, which has a $\mathrm{pH}$ of 1.3 .

\section{THE UNSTIRRED WATER LAYER AND MUCOSAL PROTECTION}

Most studies of the unstirred layer have been concerned with its effects on absorption. It is becoming increasingly likely, however, that the presence of an unstirred layer at the gastric mucosal surface is of importance in explaining the resistance of the mucosa to the development of acute hemorrhagic erosions following exposure to necrotizing agents. Stimulation by prostaglandins of alkaline secretion and mucus release could produce an increase in the thickness of the juxtamucosal unstirred layer sufficient to produce physical dissipation and dilution of necrotizing agents. Duane et al (32) used a carbon monoxide diffusion technique to demonstrate an unstirred layer, approximately $880 \mu \mathrm{m}$ thick, on the surface of rat gastric mucosa. Mixing of the luminal solution resulted in a $45 \%$ decrease in the thickness of the unstirred layer (to an average thickness of about $450 \mu \mathrm{m}$ ) and significantly increased susceptibility of the mucosa to damage by bile salt.

The authors have shown that luminal stasis prior to administration of acidified sodium taurocholate or $40 \%$ 
ethanol significantly reduced the damage produced by these agents (12). Pretreatment of animals with indomethacin abolished the protective effects of luminal stasis, but this protection was restored by sucralfate. These studies suggested that impaired prostaglandin synthesis, ie, $88 \%$ inhibition of synthesis of 6-keto-prostaglan$\operatorname{din} F_{1 \alpha}$, increased the susceptibility of the mucosa in the same manner as did stirring of luminal solutions.

\section{THE $\mathrm{pH}$ GRADIENT AND CYTOPROTECTION}

The authors have studied the effects of protective mild irritants and luminal stasis on the thickness and magnitude of the juxtamucosal $\mathrm{pH}$ gradient using an ex vivo rat gastric chamber model and antimony microelectrodes. The microelectrodes had tip diameters of 40 $\mu \mathrm{m}$ and were mounted on a micromanipulator which is capable of movement in three dimensions and advancement of the microelectrode in 10 $\mu \mathrm{m}$ increments. An indifferent electrode was also positioned in the chamber and changes in hydrogen ion concentrations were recorded in millivolts on a Metrohm Herisau E512 pH meter/voltmeter. This apparatus is accurate to $0.05 \mathrm{pH}$ units. Microelectrodes were calibrated daily using standard solutions of known $\mathrm{pH}$. The beginning of the $\mathrm{pH}$ gradient was defined as the point at which the reading increased by $2 \mathrm{mV}$ or more above that of the bulk solution (equivalent to a change in $\mathrm{pH}$ of about 0.05 ). The thickness of the $\mathrm{pH}$ gradient was defined as the distance between the start of the gradient and the point at which the microelectrode touched the surface of the gastric mucosa. Placement of the electrode and contact with the mucosal surface were determined visually with a modified dissecting microscope. The change in $\mathrm{pH}$ across the gradient was defined as the magnitude of the $\mathrm{pH}$ gradient.

All of the results described in this section were obtained while bathing the gastric mucosa with $50 \mathrm{mM}$ hydrochloric acid. The gastric chamber contained stirred $(200 \mathrm{rpm}) 50 \mathrm{mM}$ hydrochloric acid during the first three
$10 \mathrm{~min}$ periods. During the fourth 10 min period the luminal solution was either stirred or unstirred. At the end of the fourth period, the luminal solution was removed and replaced with $10 \mathrm{~mL}$ of $50 \mathrm{mM}$ hydrochloric acid, and meas. urements of $\mathrm{pH}$ gradient depth and magnitude were obtained within 5 mins. Each experimental group contained five animals. Four measurements of $\mathrm{pH}$ gradient depth and magnitude were obtained from two sites on each of the dorsal and ventral surfaces of each stomach. The sites from which measurements were taken were located midway between the greater and lesser curvatures, and were equidistant from the anterior and posterior margins of the chambered mucosa.

Effects of luminal stasis on the $\mathrm{pH}$ gradient: Luminal stasis significantly $(\mathrm{P}<0.01)$ increased the thickness of the $\mathrm{pH}$ gradient from $410 \pm 20 \mu \mathrm{m}$ when the solution was stirred to $820 \pm 30 \mu \mathrm{m}$ (Fig. ure 11). In the presence of stirring, the magnitude of the gradient was only $0.30 \pm 0.05 \mathrm{pH}$ units. Luminal stasis increased the magnitude of the gradient to $1.1 \pm 0.05 \mathrm{pH}$ units. However, despite this increase, the juxtamucosal $\mathrm{pH}$ was still less than 2.5 and the mucosa was protected in this instance without the production of an alkaline zone near the surfaces of the epithelial cells. Preliminary direct measurements of the thickness of the unstirred layer have been carried out, and it is likely that the present measurements of juxtamucosal $\mathrm{pH}$ gradient are also indicative of the thickness of the unstirred layer.

Effects of indomethacin on the $\mathrm{pH}$ gradient: In earlier experiments the authors found that inhibition of prostaglandin synthesis by pretreatment with indomethacin resulted in the loss of the protection against taurocholate conferred by the $10 \mathrm{~min}$ period of luminal stasis (12). The authors' studies using the antimony microelectrodes demonstrated that indomethacin pretreatment significantly $(\mathrm{P}<0.01)$ reduced the thickness of the $\mathrm{pH}$ gradient by more than $50 \%$ to a mean of $360 \pm 20 \mu \mathrm{m}$ (Figure 11). Indomethacin also reduced the magnitude of the gradient to $0.40 \pm 0.05 \mathrm{pH}$ units.
These results indicate that impaired prostaglandin synthesis and the resulting increased susceptibility of mucosa to damage are at least partially due to a decrease in thickness of the unstirred layer/pH gradient.

Effects of inhibiting bicarbonate synthesis on the juxtamucosal $\mathrm{pH}$ gradient and on mucosal susceptibility to acute damage: The authors tested the effects of the carbonic anhydrase inhibitor, acetazolamide $(100 \mathrm{mg} / \mathrm{kg}$ subcutaneously) on the chambered gastric mucosa. Acetazolamide pretreatment abolished the protective effect of luminal stasis against taurocholate and significantly reduced both thickness (to $270 \pm 50 \mu \mathrm{m}$ ) and magnitude (to $0.25 \pm 0.05 \mathrm{pH}$ units) of the juxtamucosal $\mathrm{pH}$ gradient. These findings suggest that bicarbonate secretion is important in mucosal defence and that it is impaired by NSAIDs. They also suggest, however, that the beneficial effects of bicarbonate secretion may be due to effects on the unstirred layer as well as any effects resulting from elevation of $\mathrm{pH}$ at the mucosal surface since, even in the presence of unimpaired bicarbonate secretion, the $\mathrm{pH}$ at the mucosal surface is less than 2.5 (Figure 11).

\section{TROPHIC EFFECTS OF PROSTAGLANDINS}

Prostaglandins have marked trophic effects on the gastric mucosa. Administration of misoprostol to dogs for 11 weeks produced a $36 \%$ increase in stomach weight, primarily due to increases in length of the upper or foveolar region of the gland, and reflecting a significant increase in the gland cell production rate (33). Similar increases in thickness of the gastric mucosa, particularly in the foveolar regions, were also seen in humans after administration of 15(R)-15-methyl prostaglandin $\mathrm{E}_{2}$ for four months (34). The hyperplasia produced by prolonged treatment with prostaglandins resulted in increases in epithelial cells which secrete bicarbonate and mucus. This is the population which responds to luminal irritants and is responsible for mucosal defensive responses against 


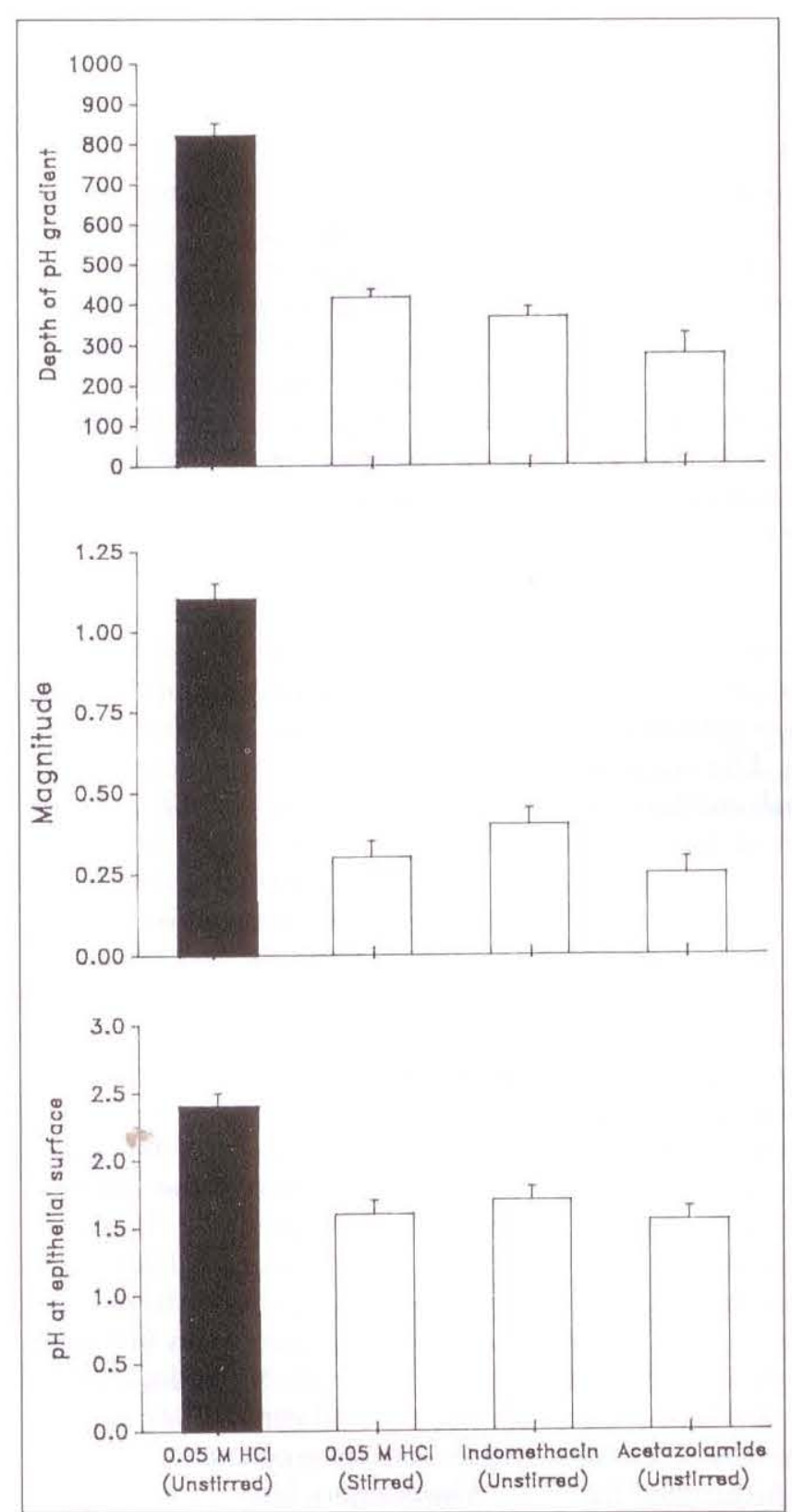

Figure 11) Effects of stirring the luminal solution with a glass paddle rotating at $200 \mathrm{rpm}$, of subcutaneous indomethacin $(5 \mathrm{mg} / \mathrm{kg}$ ) and subcutaneous acetazolamide $(100 \mathrm{mg} / \mathrm{kg})$, on the depth and magnitude of the juxtamucosal $\mathrm{pH}$ gradient and on the $\mathrm{pH}$ measured within $10 \mu \mathrm{m}$ of the luminal surface of the chambered rat gastric mucosa. The gastric chamber contained $50 \mathrm{mM}$ hydrochloric acid prior to and during all measurements with microelectrodes. All values are significantly $(P<0.01)$ less than the corresponding value for the unstirred luminal solution

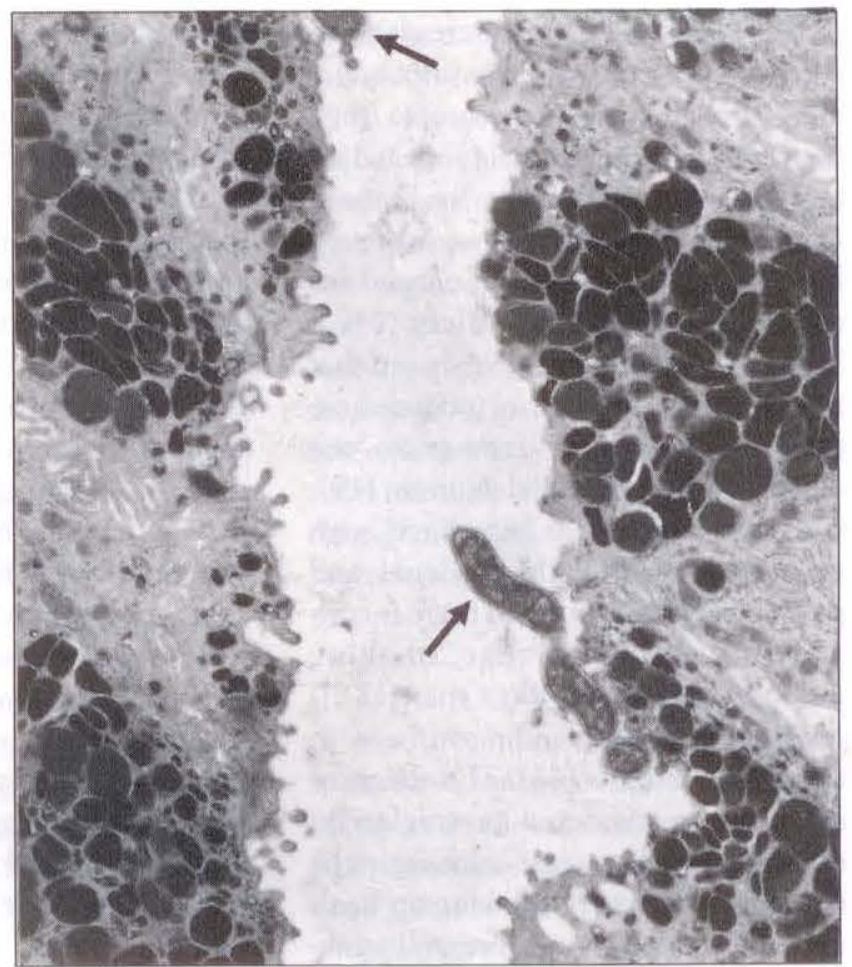

Figure 12) Transmission electron micrograph of campylobacter-like organisms (indicated by arrows) associated with surface epithelial cells in antral glands of human gastric mucosa ( $\times 6085$ )

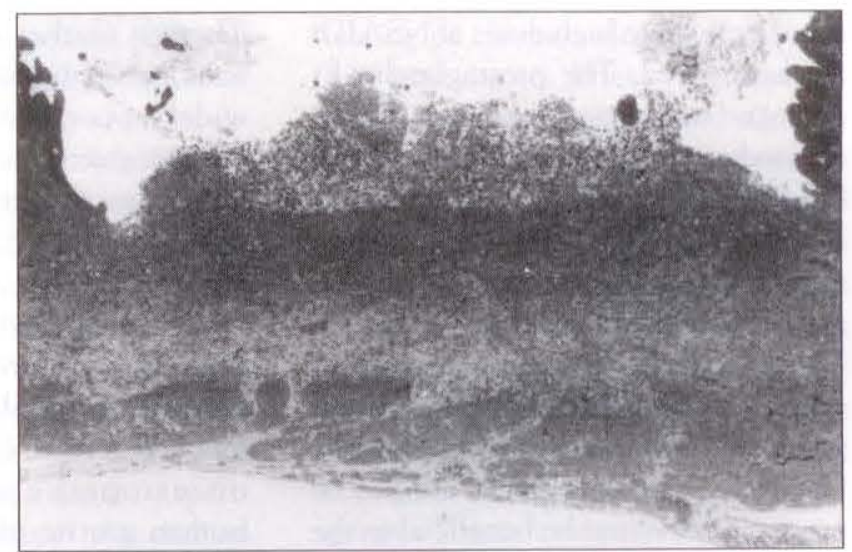

Figure 13) Light micrograph of chronic type antral ulcer from rat gastric mucosa. This ulcer was present eight days after orogastric infusion of 50 mg trinitrobenzene sulphonic acid in 50\% ethanol. (Plastic section stained with toluidine blue (X53) agents such as bile salts and excess luminal acid. Although it can be hypothesized that the changes resulting from prolonged administration of prostaglandins should render the stomach more resistant to acute damage, the authors are unaware of any published results of such experiments.

\section{PROSTAGLANDINS, MUCOSAL DEFENSES, AND DEVELOPMENT OF CHRONIC ULCER}

About four to five million North Americans suffer from peptic ulcer disease at any given time, and as much as 5 to $10 \%$ of the population may be affected during an individual lifetime (35). There are associations between depressed levels of prostaglandin synthesis and the presence of chronic ulcer $(36-38)$. The highest incidence of gastric ulcer is found among persons who ingest large quantities of NSAIDs, particularly the elderly $(39,40)$. There 
is little evidence for increased incidence of gastric ulcer in alcoholics even though acute exposure to high concentrations of ethanol produced superficial gastric damage in humans (41). Ethanol ingestion has, however, been associated with an increased incidence of duodenal ulcer (42). Moreover, the authors have shown that acute exposure to ethanol produced extensive, superficial damage to the duodenum and proximal jejunum (19). Cigarette smoking is associated with the presence of both duodenal and gastric ulcers $(42,43)$, and there is convincing evidence that smoking produces a transient (less than $12 \mathrm{~h}$ ) decrease in prostaglandin synthesis in the gastric mucosa (44). The effects of smoking on duodenal prostaglandin synthesis are less clear, although the deleterious effects of smoking on healing time and relapse rate are well established $(45,46)$.

Several studies suggest that replacement or supplementation of endogenous synthesis of prostaglandins with exogenous sources may be beneficial in situations where high doses of NSAIDs are being used. The prostaglandin $E_{1}$ analogue misoprostol has been shown to produce a significant reduction in NSAID-induced gastric lesions, a benefit which has not been demonstrated by $\mathrm{H}_{2}$ receptor antagonists (47). In addition, the reduction by misoprostol of indomethacin-induced increases in intestinal mucosal permeability in humans (48) raises the interesting possibility that exogenous prostaglandins may be beneficial in the treatment of NSAID-induced small intestinal inflammation.

Cytoprotection and the transition from acute to chronic ulcer: In considering the possible mechanisms by which prostaglandins may affect the defensive responses of the upper gastrointestinal tract, it is necessary to consider the type of damage which is under study. The majority of studies aimed at gaining an understanding of the etiology of chronic gastric ulcer have actually concentrated on the study of acute mucosal erosions, which are readily produced in animal models. These are prevented by prior ad- ministration of prostaglandins. Protection is provided in both humans and animals against a variety of damaging agents such as ASA and ethanol.

The inherent assumption in these studies has been that chronic exposure to the factors which produce acute erosions ('barrier breakers', acid, hypovolemia) will result in the development of a chronic ulcer. If prostaglandins act to prevent this acute damage, it is suggested that they will also prevent the development of chronic ulcer. In fact, it is now apparent that repeated exposure to agents or conditions which produce acute erosions does not necessarily result in chronic ulceration. Instead, the gastric mucosa may develop resistance or 'tolerance' to the ulcerogenic agents. This occurs in both humans and animals and has been demonstrated for ASA as well as for ethanol (49-52).

Only under exceptional circumstances does prolonged exposure to ulcerogenic agents produce, in animals, pathologies which bear some resemblance to human chronic ulcer. There is neither a naturally occurring analogue of human peptic ulcer nor a widely accepted animal model for chronic gastric ulcer, which can be used for studies of ulcer persistence and healing. The closest approximation to a chronic model is the acetic acid model in which the serosal application of concentrated acetic acid produces a long-lasting wound on the mucosal surface (53). Although it has no etiopathologic relevance to human gastric ulcer, the acetic acid model has proven useful in some studies of the effects of prolonged administration of prostaglandins and NSAIDs on mucosal healing $(54,55)$. Mechanisms of development of chronic ulcer: In the authors' studies on animal models of chronic ulceroinflammatory disease, the following hypotheses to explain the development of chronic ulcer have been invoked.

- Chronic ulcer is initiated by acute damage, with consequent development of acute inflammation and increased mucosal permeability.

- Chronic inflammation depends on entry into the lamina propria of a luminal antigen which is not adequately cleared by the mucosal immune system.

- Conventional therapy may produce transient healing but recurrence of acute injury or enhanced permeability in the presence of the inciting antigen will result in relapse. Products of microbial infections such as Campylobacter pylori (Figure 12) are a potential source of luminal antigens in the upper gastrointestinal tract, whereas acute erosions can have many causes, including the ingestion of NSAIDs. In addition, recent studies have demonstrated that NSAIDs produced increased permeability to macromolecules in the intestine and that prostaglandins have prevented this increased permeability (48). These effects occurred at sites in the bowel where decreased levels of luminal acid, due to the antisecretory effects of prostaglandins, would not have had a role.

Can cytoprotective prostaglandins prevent the development of chronic ulcer? The hypotheses outlined above predict that agents which prevent the development of acute hemorrhagic erosions should prevent the otherwise inevitable development of chronic ulceroinflammatory disease. The abilities of misoprostol to prevent the development of NSAID gastropathy in humans and to reverse NSAID-induced changes in intestinal permeability are consistent with these concepts.

The authors have examined the ability of prostaglandins to prevent the development of chronic ulceration of the stomach and colon in two animal models which they have developed. They found that orogastric intubation of fasted $(18 \mathrm{~h})$ female Sprague-Dawley rats with $1 \mathrm{~mL}$ of 40 or $50 \%(\mathrm{v} / \mathrm{v})$ ethanol containing $50 \mathrm{mg}$ of the hapten trinitrobenzene sulphonic acid (ethanol/TNB), produced one or more chronic type gastric ulcers (56). It was not necessary to use prior sensitization to produce these chronic lesions. In this model the concentrated ethanol produced acute damage and the hapten TNB, when complexed with tissue proteins, provided a poorly cleared antigen.

Administration of either ethanol or 


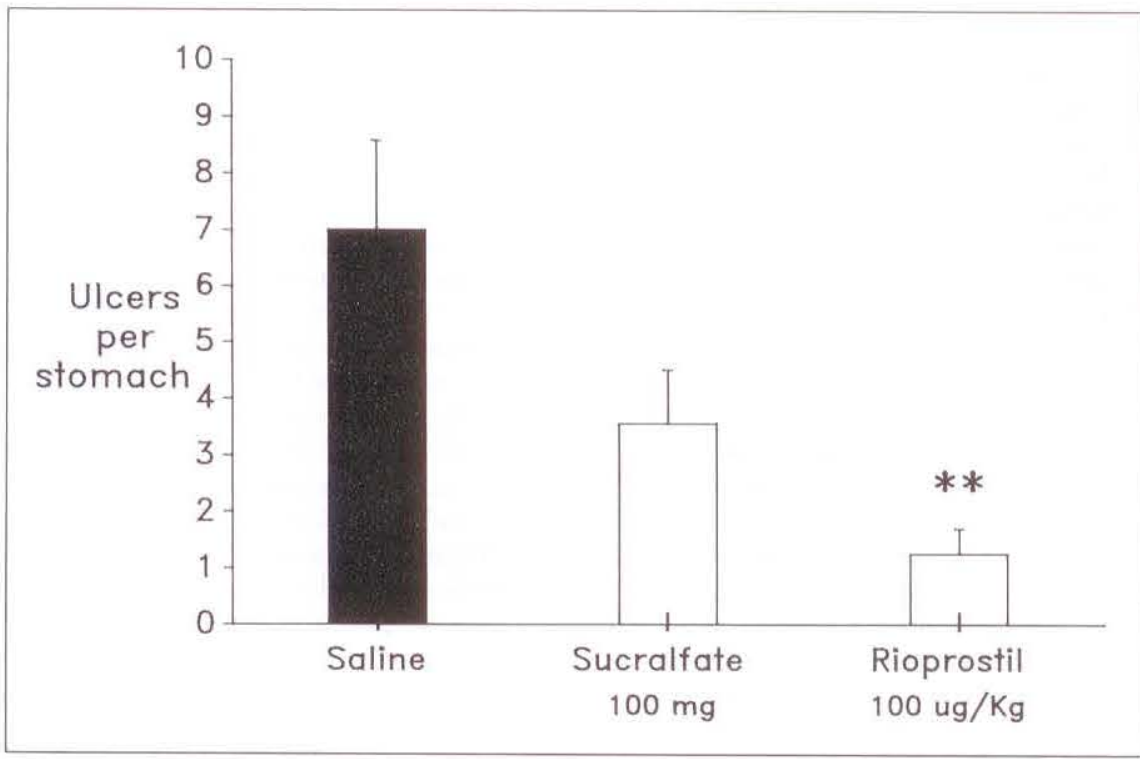

Figure 14) Effects of pretreatment with a prostaglandin $E_{1}$ analogue, with sucralfate and with saline vehicle, on the incidence of chronic type gastric ulcers present in rat stomachs five days after orogastric intubation with $50 \mathrm{mg}$ of trinitrobenzene sulphonic acid in absolute ethanol. ** $P<0.01$

ethanol/TNB produced, within $1 \mathrm{~h}$, extensive, linear, hemorrhagic erosions in the glandular mucosae of all animals. There was no difference at either $1 \mathrm{~h}$ or one day in the severity or appearance of the lesions produced by ethanol or ethanol/TNB. The acute damage produced by ethanol alone was totally healed, however, by about five days after administration, whereas $80 \%$ of the animals which received ethanol/ TNB had one or more chronic type ulcers in the antral mucosa of the lesser curvature at least five to 10 days after administration (Figure 13). The ulcers were ovoid or circular and ranged in diameter from 2 to $5 \mathrm{~mm}$. Linear, fissuring ulcers were also present in the corpus of some animals. The antral ulcers were associated with erythematous regions of gastritis, and open ulcers persisted for up to 15 days.

ACKNOWLEDGEMENTS: This research was supported by the Medical Research Council of Canada.

\section{REFERENCES}

1. Robert A, Nezamis JE, Phillips JP. Inhibition of gastric secretion by prostaglandins. Am J Dig Dis 1967;12:1073-6.

2. Miller TA. Protective effects of prosta-
In one set of experiments, the authors examined whether pretreatment of rats with cytoprotective agents would prevent the development of the chronic type gastric ulcers. Two groups of 10 rats each were fasted for $18 \mathrm{~h}$ and then given $1 \mathrm{~mL}$ of either saline or saline containing $5 \mathrm{mg} / \mathrm{kg}$ of 16,16 -dimethyl prostaglandin $\mathrm{E}_{2}$ (dmPGE $\mathrm{d}_{2}$ ), followed 20 mins later by $50 \mathrm{mg}$ of TNB in $1 \mathrm{~mL} 100 \%$ ethanol. After seven days the animals were sacrificed, and the number and size of chronic type ulcers in the gastric mucosae were determined. Pretreatment with $\mathrm{dmPGE}_{2}$ reduced the mean lesion number from 4.8 per animal to zero. In a similar experiment in which the effects of sucralfate $(100 \mathrm{mg})$ and the $\mathrm{PGE}_{1}$ analogue rioprostil $(100 \mu \mathrm{g} / \mathrm{kg})$ were tested for their ability to prevent gastric ulcers, only rioprostil produced a significant de-

glandins against mucosal damage: Current knowledge and proposed mechanisms. Am J Physiol 1983;245:G601-23.

3. Robert A, Nezamis JE, Phillips JP. Effect of prostaglandin $E_{1}$ on gastric secretion and ulcer formation in the rat. Gastroenterology 1968;55:481-7.

4. Robert A, Schultz JR, Nezamis JE, Lancaster C. Gastric antisecretory antiulcer properties of $\mathrm{PGE}_{2}, 15$-methyl $\mathrm{PGE}_{2}$, and 16,16-dimethyl $\mathrm{PGE}_{2}$. crease at day 5 after intubation with 2 $\mathrm{mL} 100 \%$ ethanol containing $50 \mathrm{mg}$ TNB (Figure 14). In experiments on a model for chronic, transmural inflammation of the colon, the authors found that rioprostil, when given 20 mins before intracolonic infusion with ethanol/TNB, also significantly reduced the severity of the resulting chronic inflammation (57). In these models, the protective effects of the prostaglandins probably reflected their ability to prevent acute damage, and thus to decrease entry of the reactive hapten $(\mathrm{TNB})$ into the lamina propria (58).

\section{CONCLUSION}

It is becoming apparent that the gastrointestinal mucosa relies for its defence on a series of dynamic responses. The beneficial effects of prostaglandins cannot be entirely explained with reference to their effects on only one aspect of this defensive repertoire. The abilities of prostaglandins to suppress acid secretion and modify NSAID-induced changes in mucosal permeability could aid in both the healing of chronic ulcer and prevention of relapse. Effects on mucosal bloodflow, mucus release and alkaline secretion could explain resistance to the development of acute erosions and accelerated recovery from acute damage. Similarly, protection against acute damage can also result from trophic effects and prevention by prostaglandins of the high amplitude gastric contractions which result from exposure to various ulcerogenic procedures and agents. These 'cytoprotective' effects may, by preventing acute injury, also prevent the initial stage necessary for the production of chronic ulcer or for relapse of healed ulcer.
Intravenous, oral and intrajejunal ad. ministration. Gastroenterology 1976;70:359-70.

5. Robert A, Nezamis JE, Lancaster C, Handar J. Cytoprotection by prostaglandin in rats. Prevention of gastric necrosis produced by alcohol, $\mathrm{HCl}$, $\mathrm{NaOH}$, hypertonic $\mathrm{NaCl}$, and thermal injury. Gastroenterology 1979;77:433. 43.

6. Robert A, Nezamis JE, Lancaster C, Davis JP, Field SO, Hanchar AJ. Mild 
irritants prevent gastric necrosis through 'adaptive cytoprotection' mediated by prostaglandins. Am J Physiol 1983;245:G113-21.

7. Guth PH, Paulsen G. Aspirin-induced gastric injury in the rat: Histologic changes and sucralfate cytoprotection. Proc Soc Exp Biol Med 1987; 184:423-8.

8. Domschke W, Hagel ], Ruppin H, Kaduk B. Antacids and gastric mucosal protection. Scand J Gastroenterol 1986;21 (Suppl 125):144-9.

9. Morris GP, Keenan CM, Shriver DA. Morphological and physiological effects of a cytoprotective prostaglandin analog (rioprostil) on the rat gastric mucosa. Clin Invest Med 1987;10:121-31

10. Hawkey CJ, Kemp RT, Walt RP, Bhaskar NK, Davies J, Filipowicz B. Evidence that adaptive cytoprotection in rats is not mediated by prostaglandins. Gastroenterology 1988;94:948-54.

11. MacNaughton WK, Williamson TE, Morris GP. Adaptive cytoprotection by $0.25 \mathrm{M} \mathrm{HCl}$ is truly 'cytoprotective' and may not depend upon elevated levels of prostaglandin synthesis. Can ] Physiol Pharmacol 1988;66:1075-81.

12. Morris GP, Keenan CM, MacNaughton WK, Wallace JL, Williamson TE. Protection of rat gastric mucosa by sucralfate: Effects of lumigal stasis and of inhibition of prostaglandin synthesis. Am J Med 1989;86(Suppl 6A):10-6.

13. Cherner JA, Naik L, Tarnawski A, Brzozowski T, Stachura ], Singh G. Ability of prostaglandin to reduce ethanol injury to dispersed chief cells from guinea pig stomach. Am J Physiol 1989;256:G704-14.

14. Terano A, Hiraishi H, Ota S, Sugimoto T. Cytoprotection by prostaglandins in cell culture. In: Hayaishi $\mathrm{O}$, Yamamoto S, eds. Advances in Prostaglandin, Thromboxane and Leukotriene Research. New York: Raven Press, 1985:655-6.

15. Terano A, Mach T, Stachura J, Tarnawski A, Ivey KJ. Effect of 16,16dimethyl prostaglandin $\mathrm{E}_{2}$ on aspirin-induced damage to rat gastric epithelial cells in tissue culture. Gut 1984:25:19-25.

16. Szabo S, Hollander D. Pathways of gastrointestinal protection and repair: Mechanisms of action of sucralfate. Am J Med 1989;86(Suppl 6A):23-31.

17. Morris GP. Prostaglandins and cellular restitution in the gastric mucosa. Am J Med 1986;81(Suppl 2A):23-9.

18. Ivey KJ, Baskin WN, Krause WJ, Terry B. Effect of aspirin and acid on human jejunal mucosa. An ultrastructural study. Gastroenterology 1979;76:50-6.

19. Millan MS, Morris GP, Beck IT, Henson JT. Villous damage induced by suction biopsy and by acute ethanol intake in normal human small intestine. Dig Dis Sci 1980; 35:513.25.

20. Gannon B, Browning J, O'Brien P, Rogers P. Mucosal microvascular architecrure of the fundus and body of human stomach. Gastroenterology 1984;86:866-75.

21. Gannon B, Browning J, O'Brien P. The microvascular architecture of the glandular mucosa of the rat stomach. J Anat 1982;135:667-83.

22. Whittle BJR, Kauffman GL, Moncada S. Vasoconstricion with thromboxane $\mathrm{A}_{2}$ induces ulceration of the gastric mucosa. Nature 1981;292:472-4.

23. Kauffman GL, Grossman MI. Prostaglandin and cimetidine inhibit the formation of ulcers produced by parenteral salicylates. Gastroenterology 1978;75:1099-102.

24. Whittle BJR. The potentiation of taurocholate-induced rat gastric erosions following parenteral administration of cyclooxygenase inhibitors. $\mathrm{Br}$ J Pharmacol 1983;80:545-51.

25. Oates PJ, Hakkinen JP. Studies on the mechanism of ethanol-induced gastric damage in rats. Gastroenterology 1988;94:10-21

26. Morris GP, Wallace JL. The roles of ethanol and of acid in the production of gastric mucosal erosions in rats. Virchows Arch [B] 1981;38:23-38.

27. Wallace JL, Morris GP, Krausse EJ, Greaves SE. Reduction by cytoprotective agents of ethanol-induced damage to the rat gastric mucosa: A correlated morphological and physiological study. Can J Physiol Pharmacol 1982;60:1686-99.

28. Beck PL, Morris GP, Wallace JL. Reduction of ethanol-induced gastric damage by sodium cromoglycate and FPL-52694. Role of leukotrienes, prostaglandins, and mast cells in the protective mechanism. Can J Physiol Pharmacol 1989;67:287-93.

29. Wallace JL, Beck PL, Morris GP. Is there a role for leukotrienes as mediators of ethanol-induced gastric mucosal damage? Am J Physiol 1988;254:G117-23.

30. Donaldson CL, Morris GP. Local and 'referred' cytoprotection by mild irritants and a PGE 1 analog. Gastroenterology 1988;94:A614. (Abst)

31. Turnberg LA, Ross IN. Studies of the $\mathrm{pH}$ gradient across gastric mucus. Scand J Gastroenterol 1984;19 (Suppl 92):48-50.

32. Duane WC, Levitt MD, Staley NA, McHale AP, Wiegand SM, Fetzer CA Role of the unstirred layer in protecting the murine gastric mucosa from bile salt. Gastroenterology 1986;91:913-8.

33. Goodlad RA, Madgwick AJ, Moffatt
MR, Levin S, Allen JL, Wright NA. Prostaglandins and the gastric epithelium: Effects of misoprostol on gastric epithelial cell proliferation in the dog. Gut 1989;30:316-21.

34. Tytgat GN, Offerhaus GJA, Van Minnen AJ, Everts V, Hensen-Logmans SC, Samson G. Influence of oral 15(R)-15-methyl prostaglandin $E_{2}$ on human gastric mucosa. A light microscopic, cell kinetic, and ultrastructural study. Gastroenterology 1986;90:1111-20

35. Goldberg MA. Medical treatment of peptic ulcer disease: Is it truly efficacious? Am J Med 1984;77:589-91.

36. Hillier K, Smith CL, Jewell R, Arthur MJP, Ross G. Duodenal mucosa synthesis of prostaglandins in duodenal ulcer disease. Gut 1985;26:237-40.

37. Crampton JR, Gibbons LC, Rees WDW. Simultaneous measurement of in vitro gastroduodenal prostaglandin $\mathrm{E}_{2}$ synthesis and degradation in peptic ulcer disease. Scand J Gastroenterol 1987;22:425-30.

38. Pugh S, Williams SE, Lewin MR, et al. Duodenal and antral mucosal prostaglandin $E_{2}$ synthesis in a study of normal subjects and all stages of duodenal ulcer disease treated by $\mathrm{H}_{2}$ receptor antagonists. Gut 1989;30:161-5.

39. Faulkner G, Prichard P, Somerville K, Langman MJS. Aspirin and bleeding peptic ulcers in the elderly. $\mathrm{Br}$ Med J 1988;297:1311-3.

40. Langman MJS. Anti-inflammatory drug intake and the risk of ulcer complications. Med Toxicol 1986;1(Suppl 1):34-8.

41. Gottfried EB, Korsten MA, Lieber CS. Alcohol-induced gastric and duodenal lesions in man. Am J Gastroenterol 1978; 70:587-92.

42. Piper DW, Nasiry R, McIntosh J, Shy CM, Pierce ], Byth K. Smoking, alcohol, analgesics, and chronic duodenal ulcer. Scand J Gastroenterol 1984:19:1015-21.

43. McIntosh JH, Byth K, Piper DW. Environmental factors in aetiology of chronic gastric ulcer: A case control study of exposure variables before the first symptoms. Gut 1985;26:789-98.

44. McCready DR, Clark L, Cohen MM. Cigarette smoking reduces human gastric luminal prostaglandin $\mathrm{E}_{2}$. Gut 1985;26:1192-6.

45. Guslandi M. How does smoking harm the duodenum? Br Med J 1988;296:311-2.

46. Hull DH, Beale PJ. Cigarette smoking and duodenal ulcer. Gut 1985;26:1333-7.

47. Graham DY, Agrawal NM, Roth SR. Prevention of NSAID-induced gastric ulcer with misoprostol: Multicentre, double-blind, placebo-controlled trial. Lancet 1988;ii:1277-80.

48. Bjarnson I, Smethurst P, Fenn CG, 
Lee CE, Menzies IS, Levi AJ. Misoprostol reduces indomethacin-induced changes in human small intestinal permeability. Dig Dis Sci 1989;34:407-11.

49. Graham DY, Smith JL, Spjut HJ, Torres E. Gastric adaptation. Studies in humans during continuous aspirin administration. Gastroenterology 1988;95:327-33.

50. Tepperman BL, Soper BD. Prostaglandin $\mathrm{E}_{2}$ binding sites in porcine oxyntic mucosa: Effects of salicylates. Can J Physiol Pharmacol 1986;64:515-20.

51. St John DJB, Yeomans ND,

McDermott FT, de Boer WGRM.

Adaptation of the gastric mucosa to repeated administration of aspirin in the rat. Dig Dis Sci 1973;18:881-6.

52. Ivey KJ, Tarnawski A, Stachura J,
Werner H, Mach T, Burks M. The induction of gastric mucosal tolerance to alcohol by chronic administration. J Lab Clin Med 1980;96:922-32.

53. Okabe S, Pfeiffer CJ. The acetic acid ulcer model. A procedure for chronic duodenal or gastric ulcer. In: Pfeiffer C], ed. Peptic Ulcer. Philadelphia: JB Lippincott, 1971:13-20.

54. Okabe S, Takeuchi K, Honda K, Takagi K. Effects of acetylsalicylic acid (ASA), ASA plus L-glutamine and L-glutamine on healing of chronic gastric ulcer in the rat. Digestion 1976;14:85-8.

55. Wang JY, Yamasaki S, Takeuchi K, Okabe S. Delayed healing of acetic acid-induced gastric ulcers in rats by indomethacin. Gastroenterology 1989;96:393-402.
56. Morris GP, Rebeiro L, Herridge MS, Szewczuk M, Depew WT. An animal model for chronic granulomatous inflammation of the stomach and colon. Gastroenterology 1984;86:A1188. (Abst)

57. Wallace JL, MacNaughton WK, Morris GP, Beck PL. Inhibition of leukotriene synthesis markedly accelerates healing in a rat model of inflammatory bowel disease. Gastroenterology 1989;96:29-36.

58. Allgayer H, Deschryver K, Stenson WF. Treatment with $16,16^{\prime}$-dimethyl prostaglandin $\mathrm{E}_{2}$ before and after induction of colitis with trinitrobenzene sulfonic acid in rats decreases inflammation. Gastroenterology 1989;96:1290-300. 


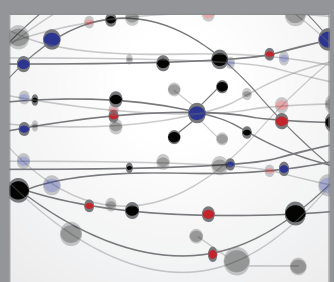

The Scientific World Journal
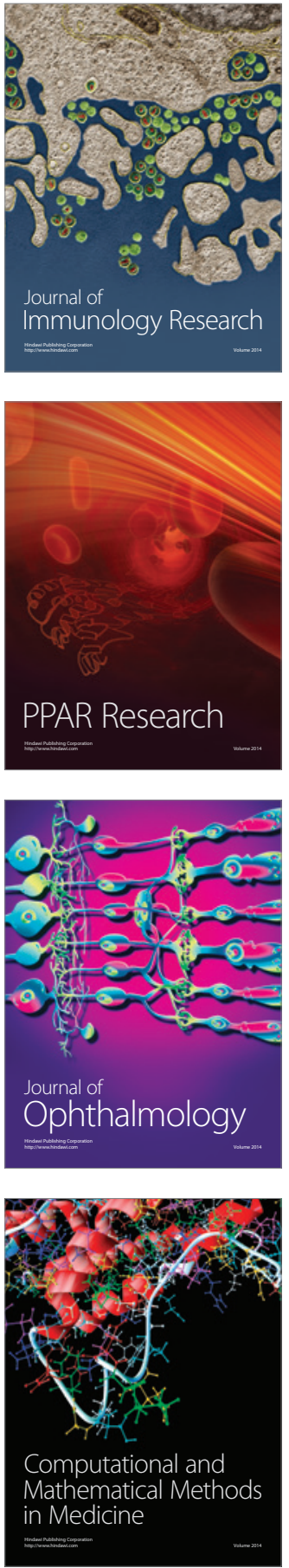

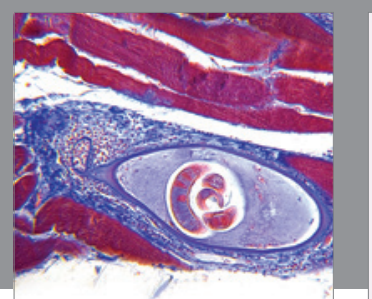

Gastroenterology Research and Practice

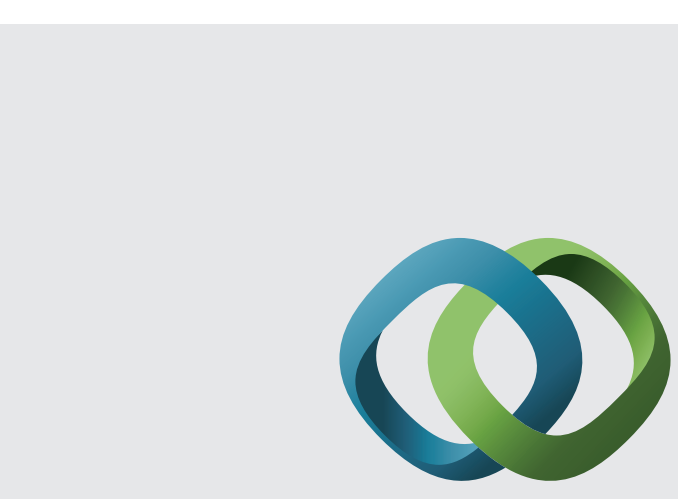

\section{Hindawi}

Submit your manuscripts at

http://www.hindawi.com
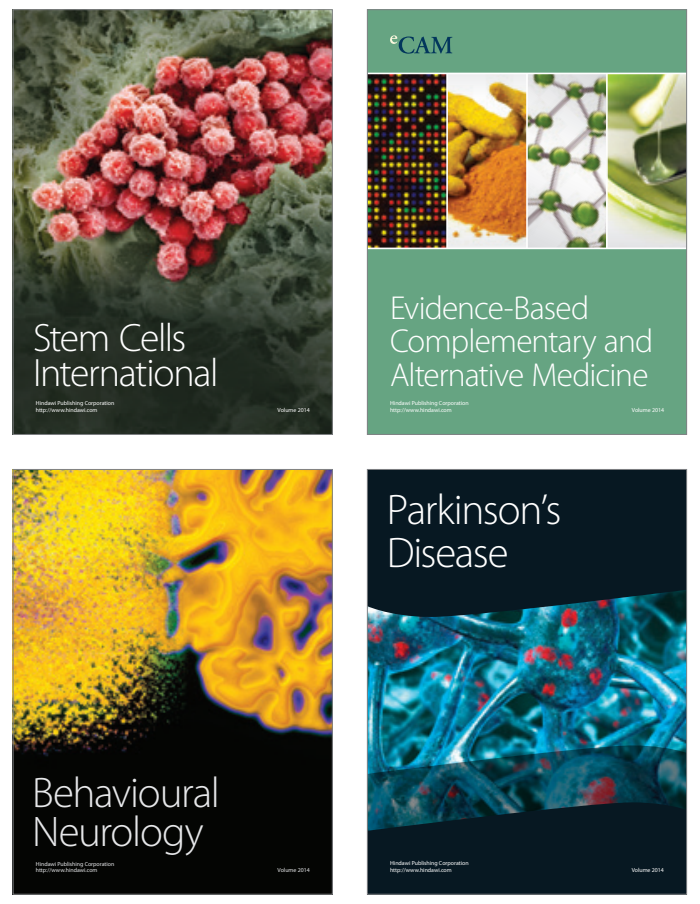
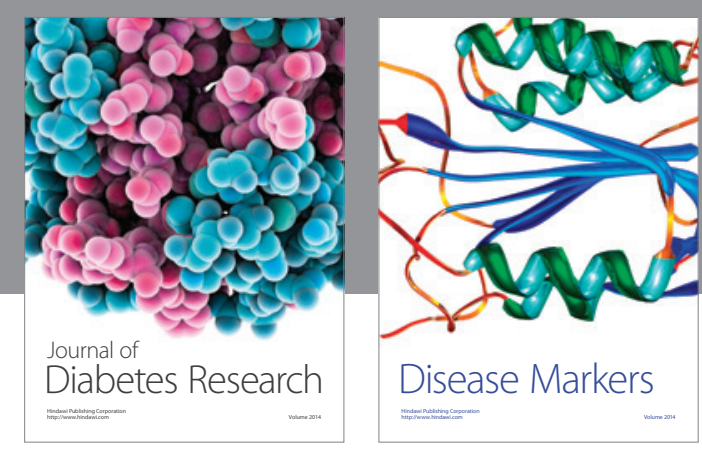

Disease Markers
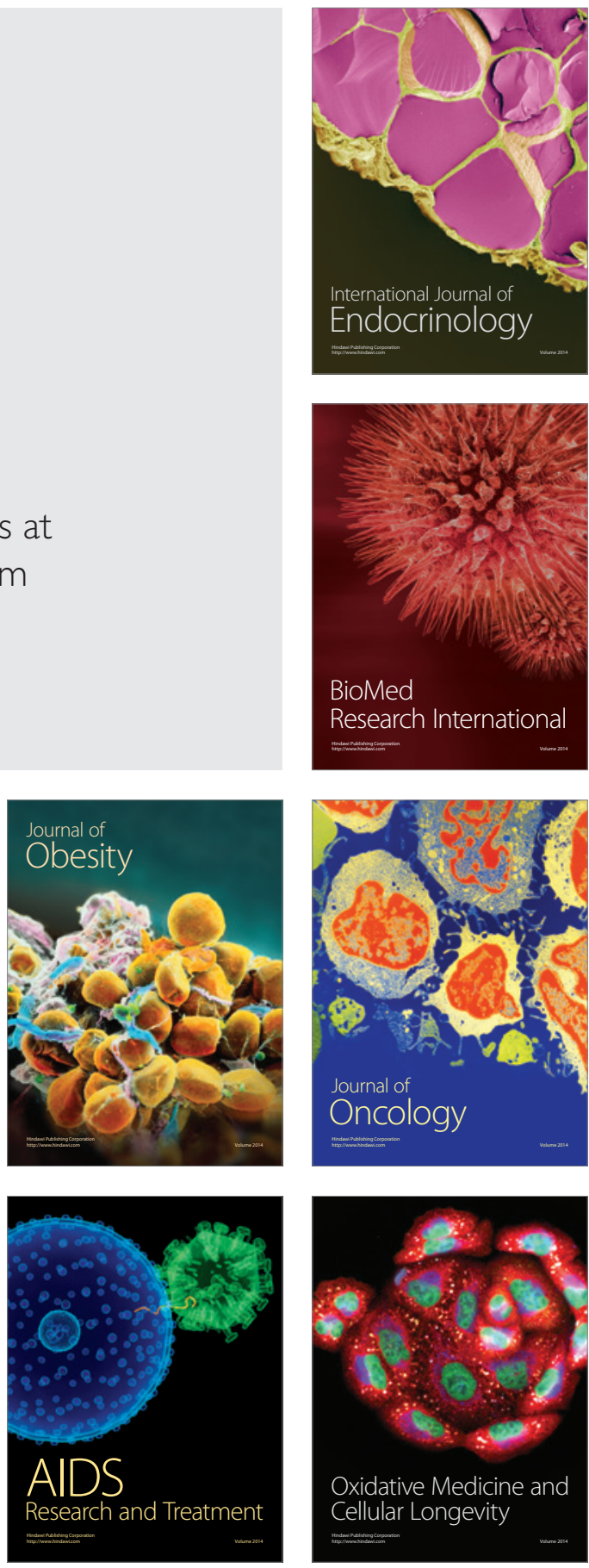